\title{
Alphabetisches Verzeichnis der Mitarbeiter dieses Bandes
}

Prof. Dr. Gerd Althoff, Historisches Institut - Mittelalter - der Universität Gießen, Otto-Behagel-Straße 10 C 2, 6300 Gießen, S. 123 und 259

Dr. Jörg W. BusCh, Sonderforschungsbereich 231, Salzstraße 41, 4400 Münster, S. 373

Prof. Dr. Christian GNILKA, Institut für Altertumskunde der Universität Münster, Domplatz 20-22, 4400 Münster, S. 1

Dr. Lotte Hedeager, Det Humanistiske Forskningscenter, Københavns Universitet, Njalsgade 80, 2300 København S, Dänemark, S. 73

Prof. Dr. Hagen Kelder, Historisches Seminar der Universität Münster, Domplatz 20-22, 4400 Münster, S. 340 und 462

Gerhard LeOpold, Oberkonservator i. R., Hufelandstraße 13, O-4059 Halle, S. 145

Prof. Dr. Gert Melville, Historisches Seminar der Universität Münster, Domplatz 20-22, 4400 Münster, S. 391

Dr. Heinz Meyer, Sonderforschungsbereich 231, Salzstraße 41, 4400 Münster, S. 315

Prof. Dr. Peter von Moos, Seminar für Mittellateinische Philologie der Universität Münster, Salzstraße 53, 4400 Münster, S. 300

Dr. Per H. RamQvist, Umeå Universitet, Institutionen för arkeologi, 90187 Umeå, Schweden, S. 45

Theodore John Rivers, Ph. D., 6407 Alderton Street, Rego Park, New York 11374, USA, S. 89

Prof. Dr. Karl Schmid, Schlehentain 12, 7800 Freiburg, S. 109

Prof. Dr. Dr. h.c. Ruth Schmidt-Wiegand, Germanistisches Institut der Universität Münster, Johannisstraße 1-4, 4400 Münster, S. 283

Dr. Wolfgang Christian Schneider, Institut für Geschichte der Technischen Hochschule Darmstadt, Residenzschloß, 6100 Darmstadt, S. 226

Prof. Dr. Ernst Schubert, Große Schloßgasse 3, O-4020 Halle, S. 188

Priv.-Doz. Dr. Nikolaus Staubach, Sonderforschungsbereich 231, Salzstraße 41, 4400 Münster, S. 418

Dr. Rotraut Wisskirchen, Burbacher Straße 22, 5300 Bonn, S. 96

Prof. Dr. Joachim Wollasch, Historisches Seminar der Universität Münster, Domplatz 20-22, 4400 Münster, S. 171 
